\title{
The Exploration of the Reform and Development of College English Teaching in the Context of the Internet Plus Era
}

\author{
Xinli Liu \\ School of Foreign Studies, Xi'an University, i'an 710065, PR China
}

Keywords: Internet Plus Era; College English teaching; Reform; Development

\begin{abstract}
The advent of the Internet Plus Era has greatly influenced people's style of life, the higher-education fieldin particular. At the forefront of new technologies, colleges and universities are facing unprecedented impact and challenges whether in educational concepts or educational methods. In the information age, in the general context of quality-oriented education, the traditional teaching methods in colleges and universities can no longer meet the requirements of society in terms of both the quality and quantity of talents. The arrival of the Internet Plus Era is an important opportunity for the reform of higher education. This paper makes a brief analysis of the problems in China's current college English teaching and proposes concrete measures in the teaching reform and development.

With the development of the times and the progress of science and technology, various changes are taking place in our work and life. Colleges and universities, at the forefront of new technologies, are most sensitive to these changes. Yet, they are relatively backward in educational methods owing to historical reasons, limited conditions and guidance of outdated educational concepts. In recent years, many scholars and men of insight have realized the seriousness of problems and have done some constructive and innovative work both in theory and practice, which, on the whole, have produced very satisfactory results. One of the innovative and forward-looking achievements is the advancement of teaching means in the context of the Internet Plus Era. How to integrate modern network technology into college English teaching is a practical problem which calls for an immediate solution on the part of the teaching staff of colleges and universities.
\end{abstract}

\section{The present situation of College English Classroom Teaching}

After many years' development, China's college English teaching have made great achievements in many respects. However, with the development of the times and the advancement of science and technology, it has lagged behind the overall development of society in many aspects. Problems with it mainly include: outdated educational concepts, passiveness of students, indifference to the modern internet-based and information-based teaching style.

\section{Outdated Educational Concepts}

The biggest problem with college English teaching is that teaching activities remain exam-oriented. Quality-oriented education, in opposition to exam-oriented education, was put forward many years ago, but the current teaching system in colleges and universities is still exam-oriented. In such a system, it is teachers who dominate the process of learning. at performance hinges on teachers. What teachers teach in class is closely related to the content of exams while why and what students study are heavily affected by exams. Weighed down with various exams, both teachers and students of English ignore the communicative function and role of the language. With the Internet available, students are in contact with myriad knowledge. However, English classes remain old-fashioned with a single pattern, where teachers, in the 45-minute class period, do the teaching without much participation of students, and therefore both the parties feel bored and unmotivated. What teachers do in class is to explain words, sentences, grammar points etc. which tends to lead to students losing interest in English study.

\section{Passiveness of Students}

In quality-oriented education, students should be the center and subject of teaching activities. However, if you take a look at our current English classes, you may find that it is teachers who, in the dominant position in classroom teaching, are the center of teaching activities. Their main jobs 
are to provide guidance for students on various exams, speed up their teaching to finish their teaching plan as scheduled. You may also find many of the teachers conduct their classroom teaching in a fixed way without much flexibility and adaptation, so what students do in class is simply to listen passively. Interaction between teachers and students are rare in class. In such a teaching mode, students lack opportunities to think independently and exercise their abilities, and therefore they merely know about English instead of knowing it. The most important link of English study- practical use- is ignored by both teachers and students.

\section{Indifference to the Modern Internet-based and Information-based Teaching Style}

Information technology and Internet technology have brought about all-round changes in our life. They can play an irreplaceable role in improving the quality of education and promoting communication between teachers and students. But currently, in China's colleges and universities, the technologies are not paid due attention to. Many people even hold the opinion that these technologies, flashy without substance, cannot produce good results in improving students' learning effect. This, on the one hand, is due to the fact that many teachers do not know much about the application of the technologies to teaching practice and, on the other hand, is related to the backward traditional teaching concepts.

\section{Challenges Posed by the Internet Plus to the Traditional English Teaching Mode}

In the context of the Internet Plus Era, the traditional English teaching mode has faced various challenges, which provide opportunities to promote English teaching in colleges and universities. Thus, we should face the challenges bravely and see them as opportunities to advance the reform of the traditional teaching mode.

With the Internet available, teaching content in traditional class seems to be insufficient, with students having easy access to information without time and place limitations. In such cases, students no longer need to always turn to teachers for help when they have problems. Instead, they can turn to the Internet, which can provide them with solutions conveniently and efficiently. What is more, in the Internet context, the way knowledge is presented to students becomes holographic, quite different from the traditional blackboard-and-chalk way. Knowledge is now presented to students on the screen with words or characters, animation, music fused together, which arouses student's interest in learning, helps them to concentrate on class activities and facilitates learning. The application of the Internet and information technologies to classroom teaching extends teaching greatly whether in terms of time length or space. On such a basis, if teachers give appropriate guidance to students, it will make a qualitative leap for students' learning effect. For instance, teachers can design some research tasks so that students can collect data and sort them out. This is followed by classroom discussions and explorations, enabling students to participate fully in the various links of teaching and learning, thus facilitating memory and application of knowledge.

In the Internet-based teaching mode, teachers can take into account almost every student's quality and features and conduct their teaching based on individual differences. Teachers and students can communicate anywhere at any time through the Internet. Compared with multi-media teaching, the Internet-based teaching paces up to great extent the flow of information. According to the collected data about students learning, teachers can adjust the direction and speed of their classroom teaching with students' problems taken into consideration.

Inevitably, such a mode will make higher demands for teachers' competence. Their role in the traditional teaching mode has been completely subverted and challenged owing to the fact that students have broader access to knowledge and that students become active. The challenges are manifested in teachers' mastery of professional knowledge and use of information-conveying tools. Teachers turn from traditional information-spreader to modern guider for students to seek knowledge. They give supportive guidance and suggestions to students in their learning process. Students become the subject of learning process. However, many university teachers lack a comprehensive mastery of information-based and Internet-based teaching means due to old age or poor professional knowledge. Further study and training are essential for them to improve their abilities. Only in this way can they do their job better and raise their teaching level. 


\section{To Construct Multivariate Blending Teaching Modes}

\section{Flipped Class Teaching Model Based on MOOC}

MOOC (massive open online course) is a modernized teaching means which integrates modernized information technology and teaching courses. People may have access to the online courses through the network terminal- computers or smart phones. Compared with traditional classroom teaching, MOOC has significant advantages in various aspects of learning: space, time, curriculum setting, target learners, motivation, way of interaction, achievement evaluation, etc.

The most attractive characteristics of MOOC is its massive teaching resources, of which some may be irrelated to the course and not applicable to teaching. When we set up a MOOC platform, we cannot simply copy the forms of other course or those of foreign countries. Instead, we should make an in-depth and detailed study of our English course, and design a MOOC platform in accordance with the characteristics of our course and expected teaching pace. In providing video and picture materials, teachers should be cautious in selection and comparison, and therefore give a reasonable arrangement of the materials and choose those materials whose content and form cater to students' needs and interest and are therefore easy for them to digest. This flipped class teaching mode based on MOOC enables even the slowest students to master knowledge points through repeated learning and practice. This saves the teacher's class time in that they need not do repeated explanations in class. For students, they have extra time to study apart from the limited class periods. What is more, in this mode, teachers can get immediate and effective feedback on students' performance and thus take correspondent measures to improve teaching quality. Consequently, both the teaching quality and learning quality will be significantly improved. With the application of the multivariate blending teaching model combining the MOOC concept with the flipped-class concept, the overall teaching process and teaching mode will be changed. By flipped class, it is meant that students need to, through the MOOC platform, preview and study their lesson, which, in traditional teaching mode, used to be taught and discussed in class, and in class, students and the teacher have discussions on their problems, which makes students have an idea of how much they have mastered about the topic and effective learning is triggered. After class, students are required to give feedback to their teacher so that he/ she can know clearly students' learning difficulties and speed, and design their follow-up teaching plans with these factors taken into account and ensure a reasonable and scientific teaching pace.

\section{Flipped Class Teaching Model Based on Micro-Lecture}

A Micro-lecture, is not simply a condensed and visualized version of a traditional college English class. It is a visualized version of an important and emphasized knowledge pointor teaching link. The visualized version is then made available on the network for students to watch after logging in. The content of a Micro-lecture mainly includes brief video material and micro-resources. Micro-resources are some PPT materials, exercises and professional testsin correspondence to the key points intended for students. Micro-lectures are not only the basis of flipped classes' being applied to college classroom teaching in China, but also an extracurricular extension of classroom teaching.

To design a flipped class based on Micro-lecture, we need pay special attention to the design and video-recording of the micro-lecture. As a distinct teaching method, a micro-lecture is very brief, different from MOOC, which is a complete video material of a lesson. Therefore, the Micro-lecture should be concise and targeted. For instance, if he/she is to record a video tape of English reading skills, the teacher should introduce reading skills briefly and concisely; he/ she should grade reading skills according to difficulty and make separate video clips to deal with them. In this way, students can move on to the next video clip after they have mastered one and improve their reading ability step by step.

The similarities between MOOC and Micro-lecture lie in the fact that they are both presented to students in the form of video clips through the Internet, but they are also different from each other in terms of content and length. Micro-lecture video clip is a brief one specially made by the teacher according to his/her pace, efficiency, difficult points, key points and students' characteristics. It is featured by clear target, straight to the point, a focus on difficult and key points and time limit to ten 
minutes. Due to these features, micro-lecture video tapes are transmitted more widely than MOOC.

\section{Conclusion}

In conclusion, with the advent of the Internet Plus Era, college English teaching in China are confronted with reforms in teaching mode, methods and concept as well as in the role of teachers. Information technology has not only brought about great impact and challenges to college English teaching, but also presented opportunities for reform and development. In the context of the Internet Plus Era, teachers of college English should make an in-depth and detailed study of teaching modes such as MOOC and Micro-lecture, combine them with flipped class teaching in a reasonable mannerin order to construct multivariate blending teaching models and raise the level of college English teaching in an all-round way.

\section{References}

[1] Shen Li. Reflections on "Internet +ESP" Mode inthe Applied Undergraduate Colleges - Taking Yangtze Normal University as an Example [J]. Guide in Science, Technology and Economy, 2017 (26): 191-192+197.

[2] Xu Laiyong. An Exploration of the Blending Teaching Mode and Strategies in College English Teaching in the Context of the "Internet Plus [J]. Journal of Lanzhou Institute of Education, 2017,33 (02): 137-138.

[3] Zhao Dandan. Teaching Design Featured with the Integration of IT and college English Teaching in the Context of "Internet Plus Education"[J]. Journal of Jiamusi Vocational College, 2017 (02): 407.

[4] Cao Gui Hua. On the Important Influence of Internet and Information Technologies on English Teaching Mode -- Comment on Introduction of Integrated Teaching Mode of Network environment and College English Course, [J]. news enthusiasts, 2016 (11): 93-94.

[5] Yu Kaiyuan, Chi Xiaoxing, Qian Li Li, The Construction of University Chemistry Courses in the Age of Big Data-Taking the Teaching of Physicsand Chemistry as an Example, [J]. Agricultural Products Processing, 2016 (16): 74-76.

[6] Huang Fan. The Way of Professional Development of College English Teachers under the Background of Classified Teaching Reform -- Taking the College English Department of Lishui College as an Example, [J]. Western Quality Education, 2016,2 (10): 10-11.

[7] Yu Yang. Content-based College English Teaching Design with "Online shopping" as the Theme [J]. Journal of Southwest National University (Humanities \& Social Sciences), 2012,33 (S1): 224-226.

[8] Yuan Xiaowei. Current Situation of Information-based College English Teaching under the Background of Network and Reform Proposals [J].Journal of Jiamusi Vocational College2016 (07): 408-409.

[9] Ni Danping, Wang Jin, Zhu Yu. Research on the Application of the Flipped Class Teaching Modein College English Teaching in Private Colleges and Universities [J]. Overseas English, 2016 (09): 43-44.

[10]Zhao Yun. An Exploration of Reform Measures of College English Teaching in the "Internet Plus" Age [J]. Journal of Jilin RTV University, 2016 (12): 146-147.

[11]FengYuanzheng. On the Improvement of Flipped Class on Students' Performance in Vocational Colleges [J]. Journal of TonglingVocational College of Technology, 2016,15 (04): 79-82.

[12] Yang Xiaoli. Research on the Development of Students' Autonomous Learning Ability Based on Network Multimedia Teaching of Tea English [J]. Fujian Tea, 2017,39 (10): 223-224. 